\title{
Four flavonols from the seed of Hibiscus sabdariffa Linn. growing in Binh Thuan Province
}

\author{
Pham Nguyen Kim Tuyen ${ }^{1}$, Truong Van Tien ${ }^{2}$, Tran The Anh Huy ${ }^{1}$, Nguyen Thi Hoa ${ }^{1}$, Huynh Bui Linh Chi ${ }^{3}$, \\ Nguyen Thi Hoai Thu ${ }^{4}$, Duong Thuc Huy ${ }^{5,}$, Nguyen Kim Phi Phung ${ }^{6}$
}

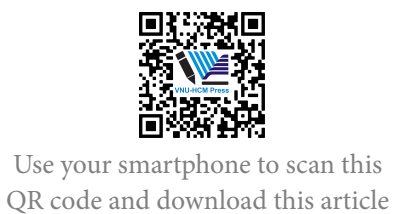

${ }^{1}$ Faculty of Environmental Science, Sai Gon University, Ho Chi Minh City

${ }^{2}$ High School Education Office, Department of Education and Training of Binh Thuan Province

${ }^{3}$ Department of Nature, Dong Nai University, Dong Nai Province

${ }^{4}$ Faculty of Basic Science, University of Medicine and Pharmacy, Ho Chi Minh City

${ }^{5}$ Faculty of Chemistry, Ho Chi Minh City University of Education, Ho Chi Minh City, Vietnam

${ }^{6}$ Faculty of Chemistry, University of Science, Ho Chi Minh City

\section{Correspondence}

Duong Thuc Huy, Faculty of Chemistry, Ho Chi Minh City University of Education, Ho Chi Minh City, Vietnam

Email: huydt@hcmue.edu.vn

History

- Received: 2019-06-25

- Accepted: 2019-11-01

- Published: 2019-11-30

DOI : 10.32508/stdj.v22i4.1690

\section{Check for updates}

\section{Copyright}

(c) VNU-HCM Press. This is an openaccess article distributed under the terms of the Creative Commons Attribution 4.0 International license.

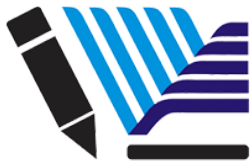

VNU-HCM Press

\begin{abstract}
Introduction: Hibiscussabdariffa Linn. (Malvaceae) is a medicinal plant popularly distributed in Asian countries. As of 2019, no chemical investigations from the Vietnamese plant were found. This paper reported the isolation and elucidation of compounds isolated from the seeds of Hibiscus sabdariffa Linn. (Malvaceae) growing in Binh Thuan province. Method: The maceration was applied to the seeds of the plant to afford the crude extract which was then fractionated by liquid-liquid extraction to obtain the ethyl acetate extract. The extract was carried out by using normal phase silica gel column chromatography and thin-layer chromatography. Analysis of spectroscopic data including HR-ESI-MS, 1D and 2D-NMR and a comparison of the NMR data with that in the literature led to the structural elucidation of isolated compounds. Results: Four flavonols comprising quercetin 3O- $\alpha$-L-rhamnopyranosyl-(1 $\rightarrow 6$ )- $\beta$-D-glucopyranoside (1), quercetin 3-O- $\beta$-D-glucopyranoside (2), quercetin (3) and kaempferol (4) were isolated from the ethyl acetate extract. Conclusions: This is the first time the isolated compounds were found from the seeds of this plant.
\end{abstract}

Key words: Hibiscus sabdariffa Linn, Malvaceae, flavonols, quercetin

\section{INTRODUCTION}

Hibiscus is one of the largest Malvaceae genera and comprises about 300 species widely distributed in Central and West Africa, and South East Asia ${ }^{1,2}$. Hibiscus sabdariffa Linn. (Malvaceae) can be used as herbal drinks, beverages and flavouring agents. Leaves and powdered seeds of $H$. sabdariffa are used as foods in West Africa ${ }^{2}$. The plant has traditionally been used in Mexico for the treatment of hypertension, diaphoretic, diuretic and hyperlipidemia ${ }^{3}$. In Vietnam, this plant is an important medicinal plant ${ }^{1}$ with folk treatments. Various chemical investigations on flowers, calyces, and leaves of $H$. sabdariffa were reported so far, providing a number of organic compounds such as phenolic acid, pectin, polysaccharides, anthocyanin and flavonoids. Nevertheless, the phytochemical data on Vietnamese H. sabdariffa plants have not been studied while the chemical constituents of the seeds of $H$. sabdariffa are scarce with the reports of fatty acids, proteins, lipids ${ }^{4}$. More recently, Habid and coworkers $(2015)^{5}$ only reported the presence of ellagic acid in the seeds of $H$. sabdariffa via LCMS without isolation ${ }^{5}$.

The current manuscript reports on the isolation of several metabolites from the seeds of $H$. sabdariffa growing in Vietnam using various chromatographic methods consisting of normal phase silica gel column chromatography and thin-layer chromatography on the ethyl acetate extract. The chemical structures of isolated compounds were elucidated based on 1D, 2D NMR, and MS along with comparison with the data in the literature. As a result, four compounds have been afforded, including quercetin $3-O-\alpha$-Lrhamnopyranosyl-( $1 \rightarrow 6)-\beta$-D-glucopyranoside (1), quercetin 3 -O- $\beta$-D-glucopyranoside (2), quercetin (3) and kaempferol (4). This is the first time the isolated compounds found from the seed of this plant.

\section{MATERIALS AND METHODS}

\section{General experimental procedures}

The HR-ESI-MS and ESI-MS spectra were carried on a Bruker microTOF Q-II and a MSQ plus Mass, respectively. TLC was carried out on pre-coated silica gel $60 \mathrm{~F}_{254}$ (Merck Millipore, Billerica, Massachusetts, USA) and spots were visualized by spraying with $10 \%$ $\mathrm{H}_{2} \mathrm{SO}_{4}$ solution followed by heating. Column chromatography was conducted with silica gel 60 (0.040 $0.063 \mathrm{~mm}$ ) (HiMedia, Mumbai, India).

\section{Plant material}

The seeds of $H$. sabdariffa were collected in Lien Huong Town, Tuy Phong District, Binh Thuan Province, Vietnam in October 2016. The scientific name was identified by Dr. Dang Van Son, Institute 


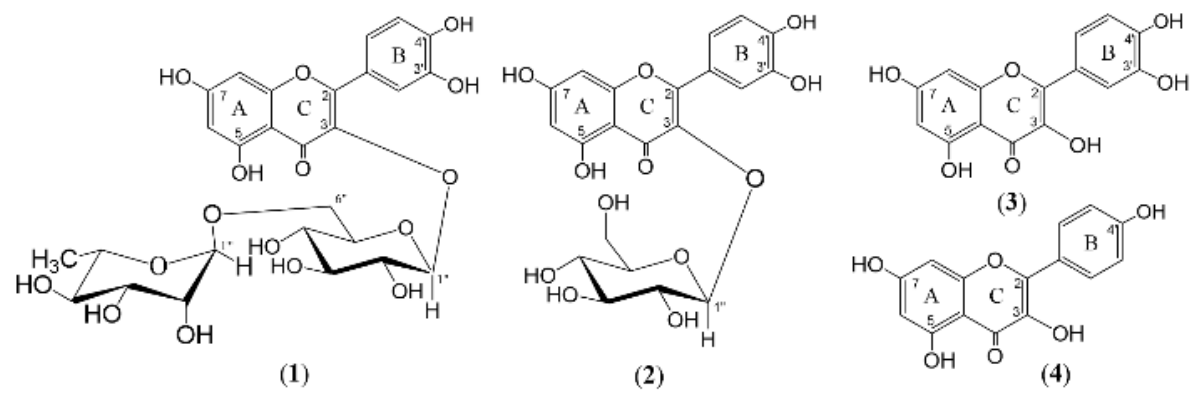

Figure 1: Structure of four isolated flavonols 1 - 4 .

of Tropical Biology, Vietnam. A voucher specimen (No.HSA/SGU-0008) was deposited in laboratory of Faculty of Environmental Science, Saigon University.

\section{Extraction and isolation}

The cleaned, air-dried and ground material (14.0 kg) was macerated in ethanol $(7 \times 5 \mathrm{~L})$ at the ambient temperature then the filtrated solution was concentrated under reduced pressure to afford the $c$ rude ethanol extract $(1.0 \mathrm{~kg})$. This crude extract was dissolved in ethanol: water $(1: 9, \mathrm{v} / \mathrm{v})$, then was partitioned with $n$-hexane, chloroform, and ethyl acetate to give $n$ hexane (140.0 g), chloroform (70.0 g) and ethyl acetate $(80.0 \mathrm{~g})$ extracts, respectively.

The ethyl acetate extract $(80.0 \mathrm{~g})$ was subjected to silica gel CC and eluted consecutively with a mixture of $n$-hexane and ethyl acetate (stepwise 8:2, 7:3, 6:4, $5: 5,4: 6,3: 7, \mathrm{v} / \mathrm{v})$ to yield 6 fractions EA1-6. Fraction EA2 (11.0 g) was applied to normal phase silica gel column chromatography, eluted with a gradient of $n$-hexane and ethyl acetate (7:3 to 6:4) to obtain 7 fractions EA2.1-7. Fraction EA2.2 (50.0 mg) was then rechromatographed using a gradient system of $n$-hexane-ethyl acetate $(8: 2$ to $7: 3, \mathrm{v} / \mathrm{v})$ to afford 3 $(32.0 \mathrm{mg})$. Fraction EA2.7 $(317.0 \mathrm{mg})$ was purified by CC, eluted with chloroform-methanol $(9: 1, \mathrm{v} / \mathrm{v})$ to afford 4 (12.0 mg). Fraction EA3 (7.5 g) was chromatographed by CC, eluted with the solvent system of n-hexane-ethyl acetate (stepwise 7:3, 6:4, 4:6, 2:8) and then methanol to yield 9 fractions EA3.1- 3.9. Fraction EA3.7 (2.3 g) was subjected to silica gel CC, eluted with $n$-hexane-ethyl acetate (stepwise 4:6, 3:7, 2:8, 1:9, $0: 1$ ) then the mixture of ethyl acetate-methanol (a gradient from 9:1- 0:1) to afford 15 subfractions EA3.7.115. Further purification of the fraction EA3.7.8 (150.0 $\mathrm{mg}$ ) using the same manner as described previously for the fraction EA3 to afford two compounds 1 (40.0 $\mathrm{mg}$ ) and 2 (27.0 $\mathrm{mg})$.

- Quercetin 3-O- $\alpha$-L-rhamnopyranosyl-( $1 \rightarrow 6)$ $\beta$-D-glucopyranose or rutin (1). Yellow amorphous powder. HR-ESI-MS, positive mode: $\mathrm{m} / \mathrm{z} 611.1611[\mathrm{M}+\mathrm{H}]^{+}$(calcd. for $\mathrm{C}_{27} \mathrm{H}_{31} \mathrm{O}_{16}$, 611.1612). The ${ }^{1} \mathrm{H}-\mathrm{NMR}$ data (DMSO- $\mathrm{d}_{6}$ ): 6.19 $(1 \mathrm{H}, \mathrm{d}, 2.0, \mathrm{H}-6), 6.38(1 \mathrm{H}, \mathrm{d}, 2.0, \mathrm{H}-8), 7.53$ $\left(1 \mathrm{H}, \mathrm{d}, 2.0, \mathrm{H}-2^{\prime}\right), 6.83\left(1 \mathrm{H}, \mathrm{d}, 8.5, \mathrm{H}-5^{\prime}\right), 7.54$ $(1 \mathrm{H}, \mathrm{dd}, 8.5,2.0, \mathrm{H}-6), 5.33(1 \mathrm{H}, \mathrm{d}, 8.5, \mathrm{H}-$ 1"), 4.39 (1H, s, H-1"'), 0.99 ( $2 \mathrm{H}, \mathrm{d}, 6.5, \mathrm{H}-6$ "') and $12.58(1 \mathrm{H}, \mathrm{s}, \mathrm{OH}-5)$. The ${ }^{13} \mathrm{C}-\mathrm{NMR}$ data (DMSO-d $)_{6}$ ): $156.4(\mathrm{C}-2), 133.3(\mathrm{C}-3), 177.4(\mathrm{C}-$ 4), $161.2(\mathrm{C}-5), 98.6$ (C-6), 164.1 (C-7), 93.6 (C8), 156.6 (C-9), 104.0 (C-10), 121.2 (C-1'), 116.2 (C-2'), 144.7 (C-3'), 148.4 (C-4'), 115.2 (C-5'), 121.6 (C-6'), 101.2 (C-1"), 74.1 (C-2”), 76.4 (C3"), 70.5 (C-4"), 75.9 (C-5”), 68.2 (C-6"), 100.7 (C-1"'), 70.3 (C-2"'), 70.0 (C-3"'), 71.8 (C-4"'), 67.0 (C-5"') and 17.7 (C-6"').

- Quercetin 3-O- $\beta$-D-glucopyranoside or isoquercitrin (2). Yellow amorphous powder. HRESI-MS, positive mode: $\mathrm{m} / \mathrm{z} 465.1028[\mathrm{M}+\mathrm{H}]^{+}$ (calcd. for $\mathrm{C}_{21} \mathrm{H}_{21} \mathrm{O}_{12}$ 465.1033). The ${ }^{1} \mathrm{H}$ NMR data (DMSO-d 6 ): $6.20(1 \mathrm{H}, \mathrm{d}, 2.0, \mathrm{H}-6)$, $6.40(1 \mathrm{H}, \mathrm{d}, 2.0, \mathrm{H}-8), 7.58\left(1 \mathrm{H}, \mathrm{d}, 2.0, \mathrm{H}-2^{\prime}\right)$, $6.84\left(1 \mathrm{H}, \mathrm{d}, 8.5, \mathrm{H}-5^{\prime}\right), 7.58(1 \mathrm{H}, \mathrm{dd}, 8.5,2.0$, H-6), 5.45 (1H, d, 8.5, H-1") and $12.63(1 \mathrm{H}, \mathrm{s}$, $\mathrm{OH}-5)$. The ${ }^{13} \mathrm{C}-\mathrm{NMR}$ data $\left(\mathrm{DMSO}-\mathrm{d}_{6}\right): 156.2$ (C-2), 133.3 (C-3), 177.4 (C-4), 161.2 (C-5), 98.6 (C-6), 164.2 (C-7), 93.5 (C-8), 156.3 (C-9), 103.9 (C-10), 121.6 (C-1'), 115.2 (C-2'), 144.8 (C-3'), 148.4 (C-4'), 116.2 (C-5'), 121.1 (C-6'), 100.8 (C-1"), 74.1 (C-2"), 76.5 (C-3"), 69.9 (C-4"), $77.5(\mathrm{C}-5 ")$ and 61.0 (C-6"). 
- Quercetin (3). Yellow amorphous powder. The ${ }^{1} \mathrm{H}-\mathrm{NMR}$ data (DMSO-d 6 ): $6.21(1 \mathrm{H}, \mathrm{d}, 2.0, \mathrm{H}-$ 6), $6.42(1 \mathrm{H}, \mathrm{d}, 2.0, \mathrm{H}-8), 7.77\left(1 \mathrm{H}, \mathrm{d}, 2.0, \mathrm{H}-2^{\prime}\right)$, $6.91(1 \mathrm{H}, \mathrm{d}, 8.5, \mathrm{H}-5$ '), $7.67(1 \mathrm{H}, \mathrm{dd}, 8.5,2.0, \mathrm{H}-$ $\left.6^{\prime}\right)$ and $12.57(1 \mathrm{H}, \mathrm{s}, \mathrm{OH}-5)$. The ${ }^{13} \mathrm{C}-\mathrm{NMR}$ data (DMSO-d ${ }_{6}$ ): 148.8 (C-2), $137.2(\mathrm{C}-3), 177.5$ (C4), 162.5 (C-5), 99.3 (C-6), 165.6 (C-7), 94.4 (C8), 158.3 (C-9), 104.5 (C-10), 124.2 (C-1'), 116.0 (C-2'), 146.2 (C-3'), 148.0 (C-4'), 116.2 (C-5') and 121.7 (C-6’)

- Kaempferol (4). Yellow amorphous powder. The ${ }^{1} \mathrm{H}-\mathrm{NMR}$ data (methanol-d4): $6.26(1 \mathrm{H}, \mathrm{d}$, 2.0, H-6), $6.53(1 \mathrm{H}, \mathrm{d}, 2.0, \mathrm{H}-8), 8.15(2 \mathrm{H}, \mathrm{d}$, 8.0, H-2', H-6'), 7.01 (2H, d, 8.0, H-3', H-5') and $12.31(1 \mathrm{H}, \mathrm{s}, \mathrm{OH}-5)$. The ${ }^{13} \mathrm{C}-\mathrm{NMR}$ data (methanol-d4): 160.4 (C-2), 137.2 (C-3), 177.4 (C-4), 164.5 (C-5), 99.3 (C-6), 165.6 (C-7), 94.4 (C-8), 158.1 (C-9), 104.5 (C-10), 123.7 (C-1'), 130.5 (C-2', C-6') and 116.2 (C-3', C-5').

\section{RESULTS AND DISCUSSION}

Compound 1 was obtained as a yellow amorphous powder. The NMR spectra of $\mathbf{1}$ revealed characteristic signals of a flavonol skeleton. Indeed, the ${ }^{1} \mathrm{H}$ NMR spectrum of $\mathbf{1}$ showed a hydroxyl group at $\delta$ $12.58(1 \mathrm{H}, s)$ which was assigned to $5-\mathrm{OH}$ of a 5,7dihydroxy A ring system in flavonoid while two meta -coupled protons at $\delta_{H} 6.19(1 \mathrm{H}, d, 2.0, \mathrm{H}-6)$ and $\delta_{H} 6.38(1 \mathrm{H}, d, 2.0, \mathrm{H}-8)$ assignable to $\mathrm{H}-6$ and $\mathrm{H}-$ 8 , respectively. Moreover, a 3',4'-dihydroxy benzene ring of 1 was defined due to the $\mathrm{ABX}$ system of three aromatic proton s at $\delta_{H} 7.53\left(1 \mathrm{H}, d, 2.0, \mathrm{H}-2^{\prime}\right), 6.83$ $\left(1 \mathrm{H}, d, 8.5, \mathrm{H}-5^{\prime}\right)$, and $7.54\left(1 \mathrm{H}, d d, 8.5,2.0, \mathrm{H}-6^{\prime}\right)$. In addition, the ${ }^{1} \mathrm{H}-\mathrm{NMR}$ spectrum also displayed signals of two sugar units including two anomeric proton s at $\delta_{H} 5.33(1 \mathrm{H}, d, 8.5, \mathrm{H}-1$ ") and $4.39(1 \mathrm{H}, s, \mathrm{H}-$ 1 ') and oxygenated methine and methylene groups in the zone of $\delta_{H}$ 3.34-3.78. Combined, 1 was defined as a flavonol glycoside ${ }^{6}$. The ${ }^{13} \mathrm{C}-\mathrm{NMR}$ spectrum was further supported this finding with the presence of 27 carbon signals, including a carbonyl carbon at $\delta_{C} 177.4(\mathrm{C}-4)$ and 14 carbons from 93.6 to $164.1 \mathrm{ppm}$ of a flavonol unit together with 12 carbons of two sugar units. The attachment of a $\beta$-Dglucopyranosyl unit was defined as C-3 due to the key $\mathrm{HMBC}$ cross peak of the anomeric proton at $\delta_{H} 5.33$ $(1 \mathrm{H}, d, 8.5 \mathrm{~Hz}, \mathrm{H}-1$ ") $)$ to C-3 $\left(\delta_{C} 133.3\right)$. Likewise, the $\alpha$-L -rhamnopyranosyl moiety connected to the $\beta$-Dglucopyranosyl unit via the linkage C-1"'-C-6", thanks to the HMBC correlation of H-1' at $\delta_{H} 4.39(1 \mathrm{H}, s$, H-1"') to C-6" ( $\left.\delta_{C} 68.2\right)$. Additionally, in the HMBC spectra, the cross peak between the anomeric proton
$\delta_{H} 4.39$ (1H, s, H-1"') and oxygenated carbon of the $\beta$-D-glucopyranosyl moiety (C-6") was observed that demonstrated the $\alpha$-L-rhamnopyranoside attached to the $\beta$-D-glucopyranosyl moiety at C- 6 ". The molecular formula of $\mathbf{1}$ was determined as $\mathrm{C}_{27} \mathrm{H}_{30} \mathrm{O}_{16}$ through the protonated molecular ion peak at $\mathrm{m} / \mathrm{z}$ $611.16110[\mathrm{M}+\mathrm{H}]^{+}$in HRESIMS, strongly supported the structure of $\mathbf{1}$. The NMR data of $\mathbf{1}$ were consistent with those of rutin ${ }^{7}$, thus $\mathbf{1}$ was determined as rutin.

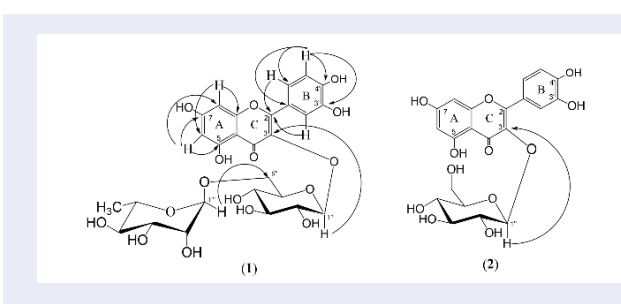

Figure 2: The key HMBC correlations of compounds 1 and 2.

Compound 2 was isolated as a yellow amorphous powder. NMR data of $\mathbf{2}$ was reminiscent to those of 1 , except for the absence of the $\alpha$-L-rhamnopyranosyl unit. The molecular formula of $\mathbf{2}$ was established as $\mathrm{C}_{21} \mathrm{H}_{20} \mathrm{O}_{12}$ based on a protonated molecular ion peak at $m / z 465.1028\left([\mathrm{M}+\mathrm{H}]^{+)}\right.$of HR-ESI-MS spectrum. NMR data of 2 was identical with those of isoquercitrin ${ }^{8}$, thus, 2 was elucidated as isoquercitrin. Compound 3 was obtained as a yellow amorphous powder. Analysis of 1D NMR data of 3 indicated that $\mathbf{3}$ had the same structure as the aglycone moiety of $\mathbf{1}$ and 2. The comparison of NMR data of 3 with those reported in the literature ${ }^{8}$ led to the chemical structure of $\mathbf{3}$ to be quercetin.

Compound 4 was isolated as a yellow powder. Comparison of NMR data of $\mathbf{4}$ and $\mathbf{3}$ resulted in their similar structure, except for the absence of the hydroxyl group at C-4' in 4 when comparing to that of 3 . NMR data of 4 was consistent with those of kaempferol reported in the literature ${ }^{6}$, accordingly, 4 was determined as kaempferol.

Rutin (1) and quercetin (3) have been described as cell-protecting agents on oxaliplatin-induced painful peripheral neuropathy based on their antioxidant properties $^{9}$. Isoquercitrin (2) and quercetin (3) revealed the strong antimicrobial and antioxidant activities $^{6}$. Particularly, quercetin (3) showed the potent antimicrobial activity against Staphylococcus aureus, with MIC value of $6.25 \mu \mathrm{g} / \mathrm{mL}^{9}$. These bioactive compounds occurred as major phenolic compounds in the extracts of leaves, flowers, and calyces of $H$. sabdariffa growing in various regions in the world. Nevertheless, 
it is worthy noting that isolated compounds $\mathbf{1}$ - $\mathbf{4}$ were found in the seeds of $H$. sabdariffa for the first time ${ }^{2}$.

\section{CONCLUSION}

From the ethyl acetate extract of the seeds of $H$. sabdariffa (Malvaceae) collected in Binh Thuan province, four compounds rutin (1), isoquercitrin (2), quercetin (3), and kaempferol (4) were isolated and elucidated using modern chromatographic and spectroscopic methods. All these compounds were known to be present for the first time from the seed of $H$. sabdariffa. Further studies on the chemical constituent and biological activity of this plant are under progress.

\section{ABBREVIATIONS}

${ }^{1}$ H NMR: Proton nuclear magnetic resonance

13 C NMR: Carbon-13 nuclear magnetic resonance

CC: column chromatography

TLC: Thin layer chromatography

HSQC: Heteronuclear single quantum coherence

HMBC: Heteronuclear multiple bond correlation

s: singlet

d: doublet

m: multiplet

\section{CONFLICTS OF INTEREST}

The authors declare no competing financial interest.

\section{AUTHOR CONTRIBUTION}

Pham N.K.T has contributed in conducting experiments, acquisition of data, and interpretation of data. Truong V.T., Tran T.A.H., Nguyen T.H., Huynh B.L.C., Nguyen T.H.T. interpreted NMR and MS data as well as searched the bibliography. Duong T.H. and
Nguyen K.P.P. gave final approval of the manuscript to be submitted.

\section{ACKNOWLEDGMENTS}

We would like to thank Dr. Dr. Dang Van Son for the identification of the scientific name.

\section{REFERENCES}

1. Pham HH. An Illustrated Flora of Vietnam. Young Publishing House. 2003;1:523-528.

2. Da-Costa-Rocha I, Bonnlaender B, Sievers H, Pischel I, Heinrich M. Hibiscus sabdariffa L. - A phytochemical and pharmacological review. Food chemistry. 2014;165:424-443.

3. Hopkins AL, Lamm MG, Funk J, Ritenbaugh C. Hibiscus sabdariffa $\mathrm{L}$. in the treatment of hypertension and hyperlipidemia: a comprehensive review of animal and human studies. Fitoterapia. 2013;85:84-94.

4. Nzikou JM, Bouanga-Kalou G, Matos L, Ganongo-Po FB, Mboungou-Mboussi PS, Moutoula FE, et al. Hibiscus sabdariffa $\mathrm{L}$. in the treatment of hypertension and hyperlipidemia: a comprehensive review of animal and human studies. Current Research Journal of Biological Sciences. 2011;3(2):141-146.

5. Habid M, Varman M, Ilham Z. Bioactive compounds of H. sabdariffa seed and Anacardium occidentale nt shell as potential natural antioxidants for biodiesell. Proceeding of International Sustainable Technology, Energy and Civilization Conference (ISTECC), Kuala Lumpur. 2015; p. 15-17.

6. Xiao ZP, Wu HK, Wu T, Shi H, Hang B, Aisa HA. Kaempferol and quercetin flavonoids from Rosa rugosa. Chemistry of Natural compounds. 2006;42(6):736-737.

7. Meng L, Liu R, Sun A, Wu S, Liu N. Separation and purification of rutin and acaciin from the chinese medicinal herb Herba cirsii by combination of macroporous absorption resin and highspeed counter-current chromatography. Journal of Chromatographic Science. 2009;47:329-322.

8. Liu H, Mou Y, Zhao J, Wang J, Zhou L, Wang M, et al. Flavonoids from Halostachys caspica and their antimicrobial and antioxidant activities. Molecules. 2010;15:7933-7945.

9. Azevedo MI, Pereira AF, Nogueira RB, Rolim FS, Wong DVT, Lima-Jnior RC, et al. The antioxidant effects of the flavonoids rutin and quercetin inhibit oxaliplatin induced chronic painful peripheral neuropathy. Chemistry of Natural compounds. 2013;9(53):1-14. 